\title{
Refractory invasive aspergillosis controlled with posaconazole and pulmonary surgery in a patient with chronic granulomatous disease: case report
}

\author{
Eda Kepenekli ${ }^{1}$, Ahmet Soysal ${ }^{1,3^{*}}$, Canan Kuzdan ${ }^{1}$, Nezih Onur Ermerak², Mustafa Yüksel ${ }^{2}$ and Mustafa Bakır
}

\begin{abstract}
Invasive aspergillosis is an important cause of morbidity and mortality in immunocompromised patients. Among primary immunodefiencies, chronic granulomatous disease (CGD) has the highest prevalence of invasive fungal diseases. Voriconazole is recommended for the primary treatment of invasive aspergillosis in most patients. In patients whose aspergillosis is refractory to voriconazole, therapeutic options include changing class of antifungal, for example using an amphotericin B formulation, an echinocandin, combination therapy, or further use of azoles. Posaconazole is a triazole derivative which is effective in Aspergillosis prophylaxis and treatment. Rarely, surgical therapy may be needed in some patients. Lesions those are contiguous with the great vessels or the pericardium, single cavitary lesion that cause hemoptysis, lesions invading the chest wall, aspergillosis that involves the skin and the bone are the indications for surgical therapy.

Chronic granulomatous disease (CGD) is an inherited immundeficiency caused by defects in the phagocyte nicotinamide adenine dinucleotidephosphate (NADPH) oxidase complex which is mainstay of killing microorganisms. CGD is characterized by recurrent life-threatening bacterial and fungal infections and by abnormally exuberant inflammatory responses leading to granuloma formation, such as granulomatous enteritis, genitourinary obstruction, and wound dehiscence. The diagnosis is made by neutrophil function testing and the genotyping.

Herein, we present a case with CGD who had invasive pulmonary aspergillosis refractory to voriconazole and liposomal amphotericine B combination therapy that was controlled with posaconazole treatment and pulmonary surgery.
\end{abstract}

Keywords: Chronic granulomatous disease, Invasive pulmonary aspergillosis, Posaconazole

\section{Background}

Chronic granulomatous disease (CGD) is a rare inherited phagocytic disorder that results in an increased susceptibility to bacterial and fungal infections and granulomatous complications $[1,2]$. CGD is characterized by the inability of phagocytes (neutrophils, monocytes, macrophages) to produce reactive oxygen species due to the absence or dysfunction of the NADPH complex [2,3]. The aberrant phagocyte function

\footnotetext{
* Correspondence: asoysal@marmara.edu.tr

'Division of Pediatric Infectious Diseases, Marmara University School of Medicine, Istanbul, Turkey

${ }^{3}$ Department of Pediatrics, Division of Pediatric Infectious Diseases, Marmara University Pendik Training and Research Hospital, Mimar Sinan Street, No:41,

Fevzi Cakmak Mah., Ust Kaynarca, Pendik, Istanbul, Turkey

Full list of author information is available at the end of the article
}

characteristic of CGD increases susceptibility to infection to catalase-positive organisms (e.g., Nocardia, Aspergillus, Serratia etc.). Hematopoietic stem cell transplantation is the only known cure for CGD [4,5]. Antimicrobial prophylaxis with trimethoprim-sulfamethoxazole and itraconazole reduces infectious complications. Supportive treatment with interferon gamma results in better outcomes in a subgroup of variant $\mathrm{X}$ linked CGD patients but its routinely usage in CGD patients remains controversial [2,6].

Aspergillus species are ubiquitous in nature, and inhalation of infectious conidia is a frequent event. Tissue invasion is uncommon and occurs in the setting of immunosuppression. Invasive aspergillosis is an important cause of morbidity and 
mortality in immunocompromised patients [1,7-10]. Among primary immunodefiencies, CGD has the highest prevalence of invasive fungal diseases estimated between $20 \%$ and $40 \%$ per patient throughout their entire life $[11,12]$. Invasive fungal disease occurs mostly during the first 2 decades, but neonatal cases have also been reported [13]. The most common fungal genus involved is Aspergillus and lungs are the most frequent localization. The diagnosis is made by fungal culture of tissues or body fluids, pathological examination of affected organs, radiological findings consistent with fungal lesions (e.g., halo sign and air-crescent sign), fungal antigen assays (galactomannan and beta-1,3-D-glucan) [14]. Therapeutic options include azole derivatives, echinocandins and amphotericin $\mathrm{B}$, but voriconazole is recommended as the first-line therapy [14]. Although diagnostic and therapeutic interventions improved in last decades many patients usually requires salvage therapy [14]. In patients whose aspergillosis is refractory to voriconazole, therapeutic options include a change of class using an amphotericin B formulation or an echinocandin, further use of azoles. Salvage treatment with posaconazole have been shown to be safe and effective $[15,16]$.

Herein, we present a case with CGD who had invasive pulmonary aspergillosis refractory to voriconazole and lipozomal amphotericine B combination therapy that was controlled with posaconazole treatment and pulmonary surgery.

\section{Case}

A 30 month-old boy presented with fever, cough, swelling and purulent discharge on upper part of his back consistent with abscess formation. Fungal culture from this abscess yielded Aspergillus spp. that was susceptible to voriconazole and amphotericin B but resistant to caspofungin. Voriconazole was given as initial monotherapy and then combined with liposomal amphotericin B because of progression of the lesions detected on computerized tomography (CT). Diagnosis of CGD was suggested by the presence of CGD history in the mother's family and an extraordinary pathogen existence in the fungal culture of the abcess. The diagnosis was confirmed with the nitroblue tetrazolium and dihidro-rhodamin oxidase assay. He was defined as X-linked CGD and gp91 CYBB gene, exon7 c.742dupA,p.Ile248AsnfsX36 molecule was defective. Interferon gamma and trimethoprim-sulfamethoxasole were given for supportive care and antimicrobial prophylaxis. Constriction of the right bronchie, consolidation of the right upper lobe including air broncograms and fistulization to the skin was detected in thorax CT (Figure 1). Antifungal combination therapy with voriconazole and amphotericin $\mathrm{B}$ was given for six months but the lesions did not regress and caused costal bone destruction. He underwent chest surgery and his destroyed right upper pulmonary lobe, upper segment of the lower lobe, two necrotic costal bones and the tract of the fistula were resected. Vertical fungal hyphaes, supurative granulomatous inflamation, fibrosis, destruction of the bone trabeculas in PAS and silver staining of surgical resection specimens were observed in pathological examination (Figure 2). Antifungal treatment was continued with posaconazole monotherapy right after surgery. Hepatic transaminase levels, serum electrolyte levels, erythrocyte sedimentation rate, C-reactive protein, complete blood count, electrocardiography (ECG) monitorized in monthly period and all were normal. Serum galactomannan antigen was 2,09 and positive right before surgery, then it was negative repeatedly. Thorax CT was repeated in every six months. In the thirty-six months follow up since from pulmonary surgery to date, no any complaints or fungal

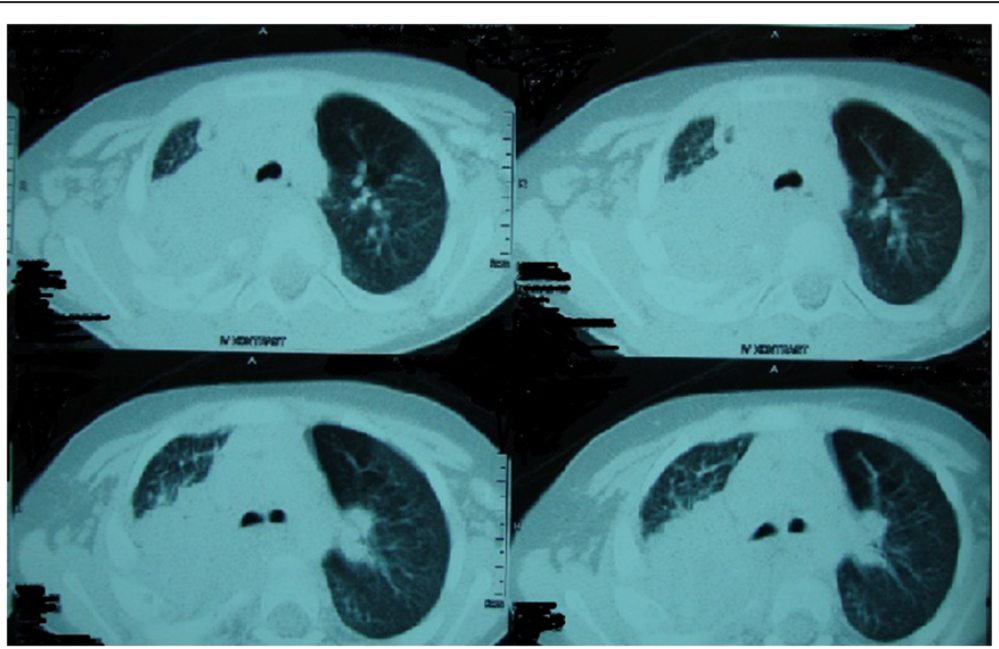

Figure 1 Computerized tomography findings consistent with expansive pulmonary involvement. 


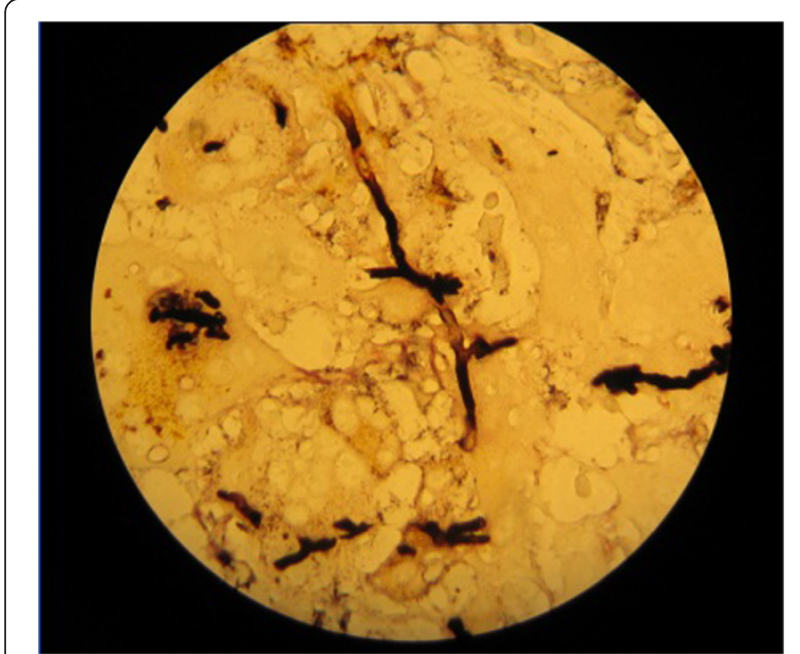

Figure 2 Vertical fungal hyphaes in PAS and silver staining of the lung resection specimens.

pulmonary or bone lesions were observed and posaconazole therapy was given continuously (Figure 3).

\section{Conclusions}

Galactomannan, a major constituent of Aspergillus cell walls that is released during the growth of hyphae, can usually be detected by enzyme immunoassay in serum, bronchoalveolar lavage fluid, cerebrospinal fluid, and pleural fluid [14]. But galactomannan is quite insensitive, even in the setting of proven infection in CGD [12]. In our patient galactomannan antigen was positive only for once before surgery and posaconazole therapy, then it was negative repeatedly.

Voriconazole is the primary therapy option for invasive pulmonary aspergillosis. Alternative therapies are liposomal and lipid complex amphotericin B, echinocandins and other

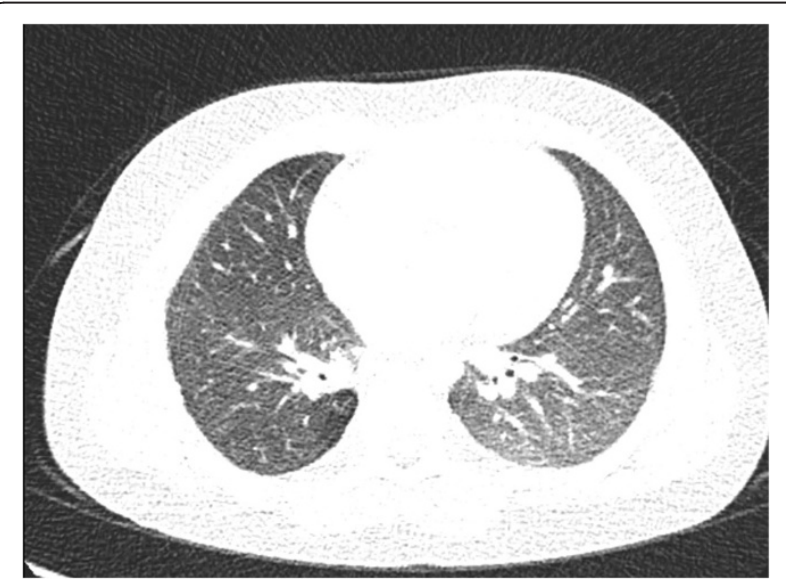

Figure 3 Thorax computerized tomography imaging which is not containing fungal lesions after surgery and posaconazole theraphy. azole derivatives such as posaconazole and itraconazole. The oral bioavailability of the azole derivatives is an advantage for the maintenance therapy after initial therapy [14]. Posaconazole is an extended spectrum triazole with invivo and invitro activity against Aspergillus species but dosage in pediatric patients has not been defined [14-16]. The posaconazole releated side effects are nausea, vomiting, anorexia, abdominal pain, dehidratation, fever, rash, throat and chest pain, headache, blurred vision and sleeplessness. The patient should be monitored for liver transaminase elevation, hypocalcemia, hypomagnesemia, hypokalemia, hyperglycemia, pancytopenia, hypertension, hypotension and, cardiac rhythm abnormalities such as QT interval prolongation [14-16]. Posaconazole was given $200 \mathrm{mg} 4$ times a day with meals to our patient right after the surgery. He received posaconazole for 36 months without any side effects.

Surgery may be useful in lesions that are contiguous with the great vessels or the pericardium, single cavitary lesion that cause hemoptysis, lesions invading the chest wall or in aspergillosis that involves the skin and the bone. Surgical resection of devitalized bone and cartilage is important for curative intent [14]. In our patient, destroyed right upper pulmonary lobe, upper segment of the right lower lobe, two necrotic costal bones and the tract of the fistula were resected, when disease progression was observed during the combined antifungal therapy.

In conclusion, we think, resection of the nonfunctional pulmonary parenchyma and devitalized bone and cartilages increased the success of posaconazole maintenance therapy.

\section{Consent}

Written informed consent was obtained from the patient's parent for the publication of this report and any accompanying images.

\section{Competing interests}

The authors declare that they have no competing interests.

\section{Authors' contributions}

MY and NOE carried out the surgical intervention. EK wrote the manuscript. CK, AS and MB contributed to the writing of the manuscript and managed the medical therapy. All authors read and approved the final manuscript.

\section{Author details}

${ }^{1}$ Division of Pediatric Infectious Diseases, Marmara University School of Medicine, Istanbul, Turkey. ${ }^{2}$ Department of Chest Surgery, Marmara University School of Medicine, Istanbul, Turkey. ${ }^{3}$ Department of Pediatrics, Division of Pediatric Infectious Diseases, Marmara University Pendik Training and Research Hospital, Mimar Sinan Street, No:41, Fevzi Cakmak Mah., Ust Kaynarca, Pendik, Istanbul, Turkey. 


\section{References}

1. Heyworth PG, Cross AR, Curnutte JT: Chronic granulomatous disease. Curr Opin Immunol 2003, 15:578-584.

2. Seger RA: Modern management of chronic granulomatous disease. BrJ Haematol 2003, 140:255-266.

3. Segal BH, Leto TL, Gallin Jl, Malech HL, Holland SM: Genetic, biochemical and clinical features of chronic granulomatous disease. Medicine 2000, 79:170-200.

4. Seger RA, Gungor T, Belohradsky BH, et al: Treatment of chronic granulomatous disease with myeloablative conditioning and an unmodified hemopoietic allograft: a survey of the European experience, 1985-2000. Blood 2002, 100:4344-4350.

5. Horwitz ME, Barret AJ, Brown MR, et al: Treatment of chronic granulomatous disease with myeloablative conditioning and t-cell depleted hematopoietic allograft. N Engl J Med 2001, 344:881-888.

6. Martire B, Rondelli R, Soresina A, et al: Clinical features, long-term follow-up and outcome of a large cohort of patients with chronic granulomatous disease: an Italian multicenter study. Clin Immunol 2008, 126:155-164.

7. Blumental S, Mouy R, Mahlaoui N, Bougnoux ME, Debré M, Beauté J, Lortholary O, Blanche S, Fischer A: Invasive mold infections in chronic granulomatous disease: a 25-year retrospective survey. Clin Infect Dis 2011, 53(12):e159-e169.

8. Mouy R, Veber F, Blanche S, et al: Long-term itraconazole prophylaxis against Aspergillus infections in thirty-two patients with chronic granulomatous disease. J Pediatr 1994, 125:998-1003.

9. Gallin Jl, Alling DW, Malech $\mathrm{HL}$, et al: Itraconazole to prevent fungal infections in chronic granulomatous disease. N Engl J Med 2003, 348:2416-2422.

10. Patterson TF, Kirkpatrick WR, White $M$, et al: Invasive aspergillosis: disease spectrum, treatment practices, and outcomes. Medicine 2000, 79:250-260.

11. Marr KA, Patterson T, Denning D: Aspergillosis: pathogenesis, clinical manifestations, and therapy. Infect Dis Clin North Am 2002, 16:875-894.

12. Falcone EL, Holland SM: Invasive fungal infection in chronic granulomatous disease: insights into pathogenesis and management. Curr Opin Infect Dis 2012, 25(6):658-669.

13. Beaute J, Obenga G, Le Mignot L, Mahlaoui N, Bougnoux ME, Mouy R, et al: Epidemiology and outcome of invasive fungal diseases in patients with chronic granulomatous disease. Pediatr Infect Dis J 2011, 30(1):57-62.

14. Walsh TJ, Anaissie EJ, Denning DW, Herbrecht R, Kontoyiannis DP, Marr KA, et al: Treatment of aspergillosis: clinical practice guidelines of the infectious diseases society of America. Clin Infect Dis 2008, 46:327-360.

15. Walsh TJ, Raad I, Patterson TF, Chandrasekar P, Donowitz GR, Graybill R, et al: Treatment of invasive aspergillozis with posaconazole in patients who are refractory to or intolerant of conventional therapy: an externally controlled trial. Clin Infect Dis 2007, 44:2-22.

16. Segal BH, Barnhart LA, Anderson VL, Walsh TJ, Malech HL, Holland SM: Posaconazole as salvage therapy in patients with chronic granulomatous disease and invasive filamentous fungal infection. Clin Infect Dis 2005, 40:1684-1688.

doi:10.1186/1824-7288-40-2

Cite this article as: Kepenekli et al:: Refractory invasive aspergillosis controlled with posaconazole and pulmonary surgery in a patient with chronic granulomatous disease: case report. Italian Journal of Pediatrics 2014 40:2.

\section{Submit your next manuscript to BioMed Central and take full advantage of:}

- Convenient online submission

- Thorough peer review

- No space constraints or color figure charges

- Immediate publication on acceptance

- Inclusion in PubMed, CAS, Scopus and Google Scholar

- Research which is freely available for redistribution 